Original article

\title{
MIDBRAIN MORPHOGENESIS IN BELUGA STURGEON (HUSO HUSO) LARVAE
}

\author{
S. H. TAVIGHI ${ }^{1}$, Z. SAADATFAR ${ }^{1}$, B. SHOJAEI ${ }^{2} \&$ M. BEHNAM RASSOULI ${ }^{3}$ \\ ${ }^{1}$ Department of Basic Science, Faculty of Veterinary Medicine, Ferdowsi \\ University of Mashhad, Mashhad, Iran; ${ }^{2}$ Department of Basic Sciences, \\ Faculty of Veterinary Medicine, Shahid Bahonar University of Kerman, \\ Kerman, Iran; ${ }^{3}$ Department of Physiological Science, Faculty of Biology, \\ Ferdowsi University of Mashhad, Mashhad, Iran
}

\begin{abstract}
Summary
Tavighi, S. H., Z. Saadatfar, B. Shojaei \& M. Behnam Rassouli, 2018. Midbrain morphogenesis in beluga sturgeon (Huso huso) larvae. Bulg. J. Vet. Med., 21, No 1, 17-27.

The subject of this study was the development of midbrain in beluga sturgeon (Huso huso) larvae. To this end, 36 larvae (6 larvae of each age) were fixed in 10\% buffered formalin, dehydrated in an ethanol series, cleared in xylene and embedded in paraffin. The larvae brain were very small in size, total head was fixed and sited in paraffin blocks. Serial sections ( $6 \mu \mathrm{m}$ thick) were stained with haematoxylin \& eosin, Luxol fast blue, cresyl echt violet and PTAH Mallory for histological studies by light microscope. A stereological study was done by the Cavalieri principle to estimate the different areas of the midbrain, about 10 sections from each specimen were selected and photographed by a camera attached to the light microscope Olympus CX22. From 1 day of age, the two parts of midbrain, optic tectum and tegmentum were obvious. There was an area between these parts called Torus semicircularis. In 6-day-old larvae, the optic tectum cell layers were partially observed and in 54-day-olds, the optic tectum occupied the largest volume of midbrain $\left(12.16 \pm 0.07 \mathrm{~mm}^{3}\right)$. Tectal ventricle in $H$. huso larvae was observed from the first day. The tegmentum was located in the ventral part of the midbrain and in its dorsal part joined the hindbrain and contained some nuclei. Stereological results showed significantly distinctive regional differences in midbrain volume $(\mathrm{P}<0.05)$. In conclusion, according to the present research, the evolution of midbrain in $H$. huso was related to ecological activities and in comparison with other ray-finned fishes was not very developed.
\end{abstract}

Key words: development, Huso huso, larva, midbrain, stereology

\section{INTRODUCTION}

The actinopterygians or ray-finned fishes comprise five superorders: Teleost (largest superorders), Cladistians, Chondrosteans (sturgeons), Ginglymods and Hale- comorphs (Kimley et al., 2002). There are about 27 sturgeon species. H. huso lives in the seas and rivers of the Northern hemisphere. Sturgeons are one of the most 
valuable fish in the world because they produce caviar and a lot of meet, and $H$. huso is the most valuable among the other sturgeons (Pinet, 2002). These fish are often benthic and live in the depth of the sea (Northcutt, 1996). H. huso swims and preys at the middle depth, requires rather light environments, and makes use of special senses for life activities. The perception of earth magnetic circuit to navigate their migration path without using other environmental factors is one of their abilities used for compensate weak visual sense (Bemis et al., 1997).

Midbrain is the visual, hearing and balance centre and a coordinator between sensory messages and motion (Kotrschal et al., 1998). In sturgeons that are mostly benthic fish, the midbrain is small (Northcutt \& Davis, 1983). It delivers imaginal impulses received from visual organs, to the brain cortex for processing and understanding the environment. The developmental differences in various parts of the brain, especially midbrain, found between sturgeons are probably caused by ecological adaptation (Ekstrom et al., 2001).

The midbrain in most fishes consists of two parts: the optic tectum which forms the top of midbrain and the ventrally situated tegmentum. Both structures are involved in multimodal sensory integration and sensory motor coordination (Nieuwenhuys, 1998). Optic tectum is a visual structure (Eastman \& Lannoo, 1995) and consists of a singular lobe in most species (Butler \& Hodos, 2005). It has, in most fish, seven cell layers (as teleostean) arranged from inside out as follow: stratum fibrosum periventriculare (SFPV), stratum griseum periventriculare (SGPV), stratum album centrale (SAC), stratum griseum centrale (SGC), stratum fibrosum et griseum superficiale (SFGS), superficial stratum opticum (SO) (Portugues \& Engert,
2009). Tectal ventricle locates at the ventral area of tectum. The other part of midbrain is torus semicircularis that mainly works to regulate the auditory and lateral line structure activities (Gibbs \& Northcutt, 2004).

The ventral part of the midbrain called tegmentum, is the main location of nuclei and nerve fibres interacting with the forebrain and hindbrain. In our review on the literature, we can only find a work on the morphogenesis of brain development in A. naccari (Vazquez et al., 2002).

The present work was designed to study the midbrain morphogenesis in $H$. huso larvae from 1 to 54 days of age.

\section{MATERIALS AND METHODS}

Thirthy-six post hatching larvae aged 1, 3, $6,15,21$ and 54 days, were obtained from the Shahid Marjani Aghghela propagation station. Six larvae of each age were fixed in $10 \%$ buffered formalin, dehydrated in ethanol series, cleared in xylene and embedded in paraffin. Because the brains were very small in size, total heads of larvae were fixed and blocked in paraffin and $6 \mu \mathrm{m}$ serial sections were prepared frontally and sagittally. The sections were deparaffinised and stained with hematoxylin \& eosin for general histological studies. Moreover the Luxol fast blue (LFB), Mallory's phosphotungstic acid-haematoxylin (Mallory's PTAH) and cresyl echt violet stainings were used in order to detect the myelin fibres, the glial cells and the Nissl bodies respectively.

Stereological studies were done by the Cavalieri principle (Gundersen \& Jensen, 1987), in order to estimate the volume of different areas of the midbrain. For this purpose, 10 sections were selected from each specimen and photographed by a camera attached to the light microscope 
(Olympus CX22). Then a point grid with distance of $0.5 \mathrm{~cm}$ was used for point counting. Grid was sited on the figures and each area from the midbrain was separately counted, then an unbiased estimate of the midbrain volume was obtained by the following formula:

$$
\mathrm{V}\left(\mathrm{mm}^{3}\right)=\mathrm{d} \times \sum \mathrm{p} \times \mathrm{a}(\mathrm{p})
$$

where: $\mathrm{d}=$ interval between sections or sections thickness; $\sum \mathrm{p}=$ total number of points considered on the area of sections; $a(p)=$ the area represented of each point in the grid.

The data were analysed by the SPSS (Version 19. SPSS Inc., Chicago, USA) and the statistical analysis was carried out by one-way ANOVA at $\mathrm{P}<0.05$ level. All results are presented as mean $\pm \mathrm{SD}$.

\section{RESULTS}

In the 1-day-old larvae, the optic tectum (OT) on the dorsal part of the midbrain, tegmentum (Teg) and torus semicircularis (ts) were obvious (Fig. 1). At this age cresyl echt violet stained the Nissl bodies (Fig. 2) and with PTAH staining, the glial cells were visible as scattered dark blue clusters in different areas of midbrain (Fig. 3).

In 6-day-old larvae, around the tectal ventricle from inside out, two areas with their nuclei were observed as followed (Fig. 4). First, the deep layer of the optic tectum; in the outer part of this layer the small pretectal nucleus of tectum (NPTec) was observed, while in the inner part of deep layer, there was a para-magnocellular (PM) nucleus nearby the tectal ventricle (Fig. 4). The second area was the superficial layer of the optic tectum: this layer was in outer part of optic tectum and more than $2 / 3$ total thickness was related to it. It contained the nerve fibres, den-

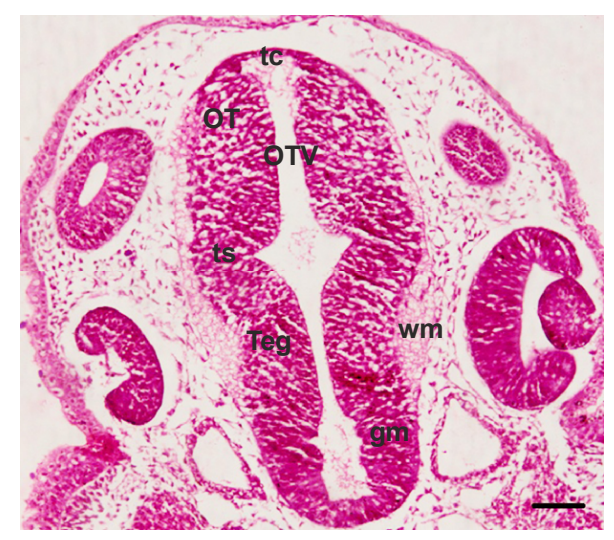

Fig. 1. Frontal section of the midbrain, 1 day of age: $t c=$ tela choroida, $O T=$ optic tectum, $O T V=$ tectal ventricle, $t s=$ torus semicircularis, $T e g=$ tegmentum, $w m=$ white matter, $g m=$ gray matter; $\mathrm{H} \& \mathrm{E}$, bar $=100 \mu \mathrm{m}$.

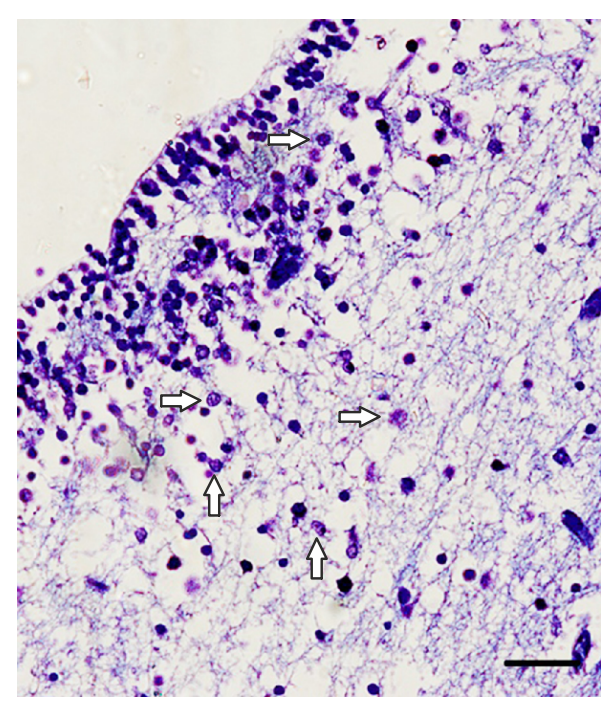

Fig. 2. Frontal section of the midbrain. Arrows show Nissl bodies; cresyl echt violet, bar $=20 \mu \mathrm{m}$.

drites and axons of deep layer of tectal neurons (Fig. 4). In the ventro-medial part of optic tectum, toward the roof of tectal ventricle, the torus longitudinalis (Tlo) was seen as a ridge on the $6^{\text {th }}$ day of development (Fig. 4). Myelin fibres were 
clearly detected by LFB staining (Fig. 5). In 54-day-old larvae, 6 cellular layers of tectum were observed from inside out: SFPV; SGPV; SAC; SGC; SFGS; SO (Fig. 6).

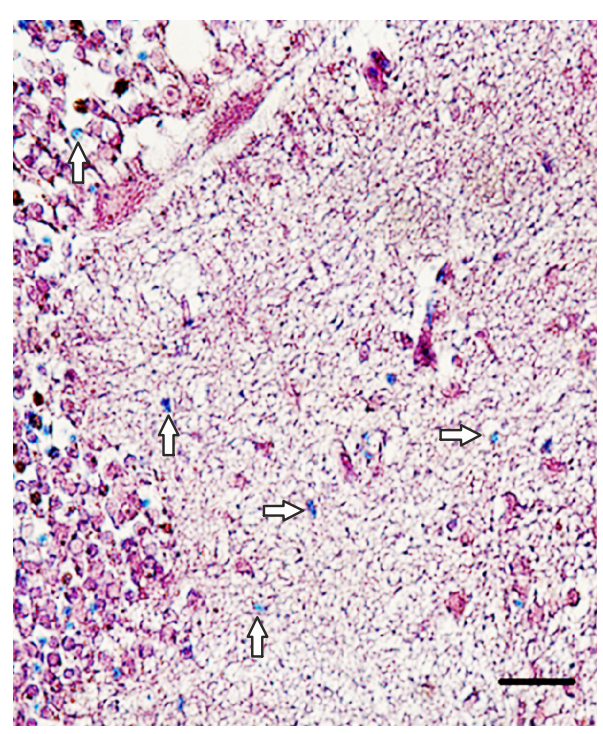

Fig. 3. Frontal section of the midbrain. Arrows show glial cells; Mallory's PTAH, bar $=20 \mu \mathrm{m}$.
In 6-day-old larvae, retinal (cone) cells (ellipsoids) were obseved as scattered conical shape and irregular rows in the dorsal and top of the tectal ventricle (Fig. 4), but rod cells were not recognised up to 54 days of age. The other structures of tectum, torus lateralis (Tla) and the valvula cerebelli (VC), were observed in 15day-old larvae. The former was in the lateral area of midbrain and the latter projected in the tectal ventricle (Fig. 7). In the lateral part of tegmentum the following areas and nuclei were diagnosed (Fig. 8): nucleus diffius (ND); lateral lemuiscus (LL); tegmentalis lateralis (1Teg), while in the medial part of tegmentum were observed nucleus glomerulosus (Gn), trochlear nucleus (Trn), oculomotor nucleus (Ocn) and tegmentalis medialis (mTeg).

At 15 days of age, sacus vasculitis (SV) was composed of small ribbon shape vascular structures. It was placed in the posterior recess of tectal ventricle. The vascular structures were lined by cuboidal to columnar cells and situated in a bed of capillaries (Fig. 8). There were three im-

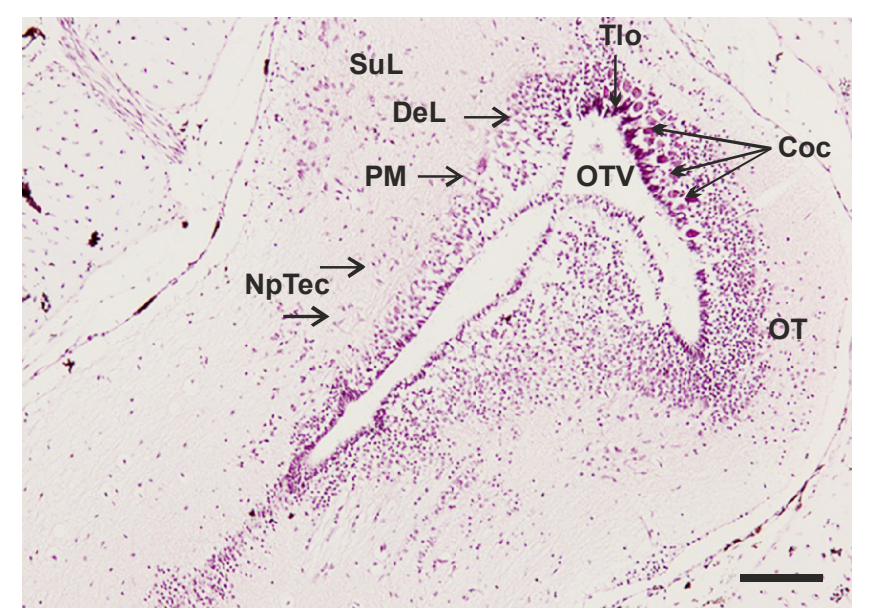

Fig. 4. Frontal section of the midbrain, 6 days of age: $C o c=$ cone cells, NPTec=pretectal nucleus of tectum, $O T=$ optic tectum, $O T V=$ tectal ventricle, $S u L=$ superficial layer of the optic tectum,

$D e L=$ deep layer of the optic tectum, $P M=$ para-magnocellular nucleus, $T l o=$ torus longitudinalis; $\mathrm{H} \& \mathrm{E}$, bar $=100 \mu \mathrm{m}$. 


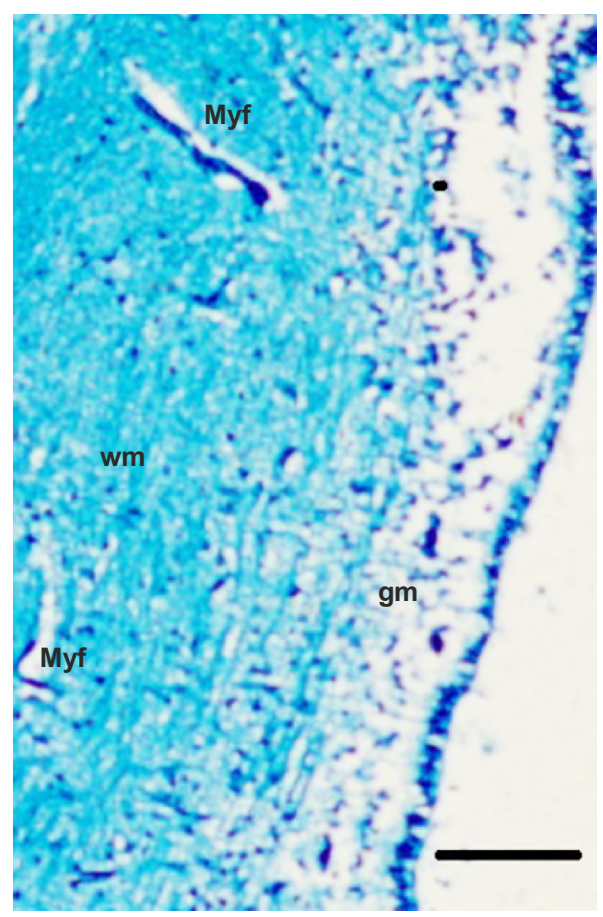

Fig. 5. Frontal section of the midbrain: $M y f=$ myelin fibre, $w m=$ white matter, $g m=$ gray matter; LFB, bar $=20 \mu \mathrm{m}$.

portant nuclei on top of SV (Fig. 8): posterior nucleus tuberculum (PNT), posterior recess nucleus (PRN) and medial nucleus of posterior tuberculum (MPT).

The tectal ventricle was observed from 1 day of age and was lined by ependymal cuboidal cells of cranial choroid plexus (Fig. 1). It expanded posteriorly to form the posterior recess. In 15-day-old larvae, a small part of valvula cerebelli was observed in the middle part of tectal ventricle. On this day, on the tectal floor, the ventricular crown cells (croc) were observed in the ependymal layer (Fig. 7). From the caudal part of tectal ventricle an extension of choroid plexus named sacus dorsalis (SD) was visible on the $54^{\text {th }}$ day (Fig. 9).

As white and gray matters were regarded, in day-old larvae, the gray matter volume was higher than that of the white matter (Fig. 1), but according to the development of myelin fibres, from the 6th day onward this ratio changed so that the gray matter in 54-day-old was evident as a thin ribbon next to the tectal ventricle (Fig. 9).

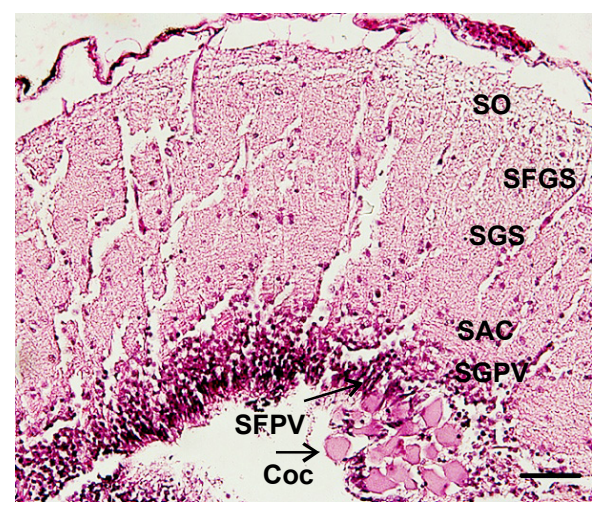

Fig. 6. Frontal section of the midbrain from 54-day-old larvae: $S O=$ superficial stratum opticum, $S F G S=$ stratum fibrosum et griseum superficiale, $S G C=$ stratum griseum centrale, $S A C=$ stratum album centrale, $S G P V=$ stratum griseum periventriculare, $S F P V=$ stratum fibrosum periventriculare, $C o c=$ cone cells; $\mathrm{H} \& \mathrm{E}$, bar $=20 \mu \mathrm{m}$.

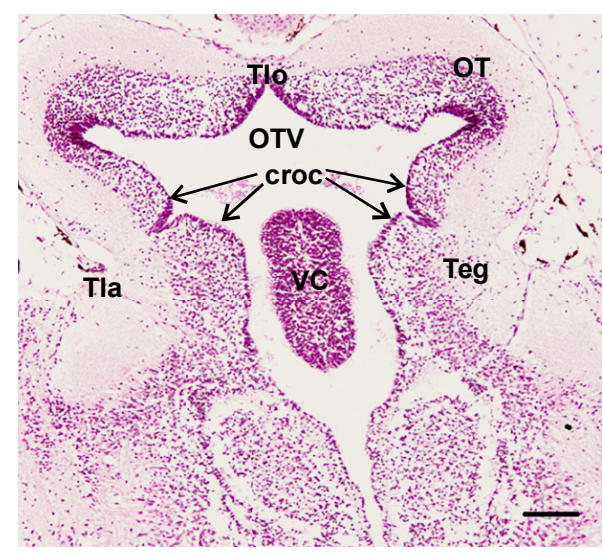

Fig. 7. Frontal section of the midbrain from 15-day-old larvae: $O T=$ optic tectum, $O T V=$ tectal ventricle, $c r o c=$ crown, $T e g=$ tegmentum, $V C=$ valvula cerebelli, $T l a=$ torus lateralis, $T l o=$ torus longitudinalis; $\mathrm{H} \& \mathrm{E}$, bar $=50 \mu \mathrm{m}$. 


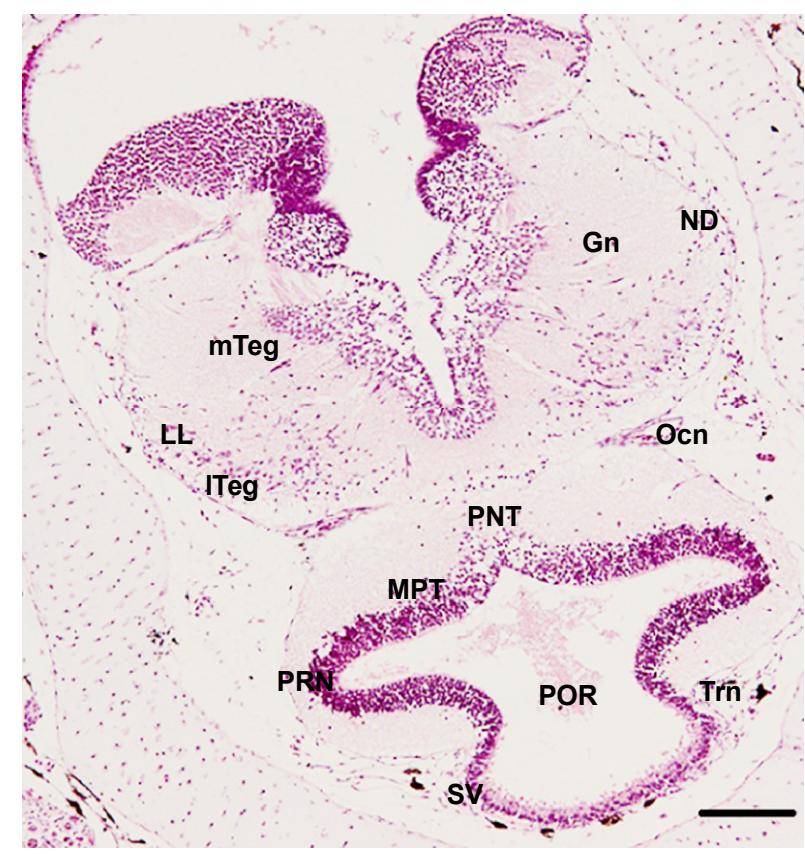

Fig. 8. Frontal section of the midbrain from 15-day-old larvae: $G n=$ glomerulosus nucleus, $N D=$ nucleus diffiuse, $l T e g=$ lateral tegmentum, $m T e g=$ medial tegmentum, $P N T=$ posterior nucleus tuberculum, $M P T=$ medial nucleus of posterior tuberculum, $S V=$ sacus vasculitis, $L L=$ lateral lemniscus, $P R N=$ posterior recess nucleus, $P O R=$ posterior recess, $O c n=$ oculomotor nucleus, $\operatorname{Tr} n=$ trochlear nucleus; $\mathrm{H} \& \mathrm{E}$, bar $=50 \mu \mathrm{m}$.

Stereological characteristics in different parts of the midbrain are summarised in Table 1. The results showed significantly distinctive differences in the volume of different parts of midbrain. This study showed that the volume of midbrain from 1 to 54 days of age increased significantly $(\mathrm{P}<0.05)$. In early stage of growth, the tegmentum volume was bigger as compared to that of the optic tectum $(\mathrm{P}<0.05)$ (Table 1). In 6-day-old larvae, the volume difference between two mentioned structures was lower and the tegmentum volume was greater than that of the optic tectum, but from the $15^{\text {th }}$ day of age, the tectum overtook the tegmentum $\left(10.7 \pm 0.07 \mathrm{~mm}^{3}\right)$ (Table 1). The volume of tectal ventricle increased from $6.06 \pm 0.16$ to $11.96 \pm 0.14 \mathrm{~mm}^{3}(\mathrm{P}<0.05)$.
The mean volume of the white matter increased (Table 1) and that of gray matter decreased $\left(6.28 \pm 0.06 \mathrm{~mm}^{3}\right)$ with aging and development of myelin fibres.

\section{DISCUSSION}

Chondrostei are a major group of rayfinned fishes whose midbrain is protected by cartilage, bone, primitive meninx membrane and adipose tissue which fills mainly partition of cavity (Nieuwenhuys, 1998).

Although the midbrain has a similar basic design, there are interesting differences in the midbrain of sturgeons and other fish. Some differences have a phylogenetic importance and show them- 


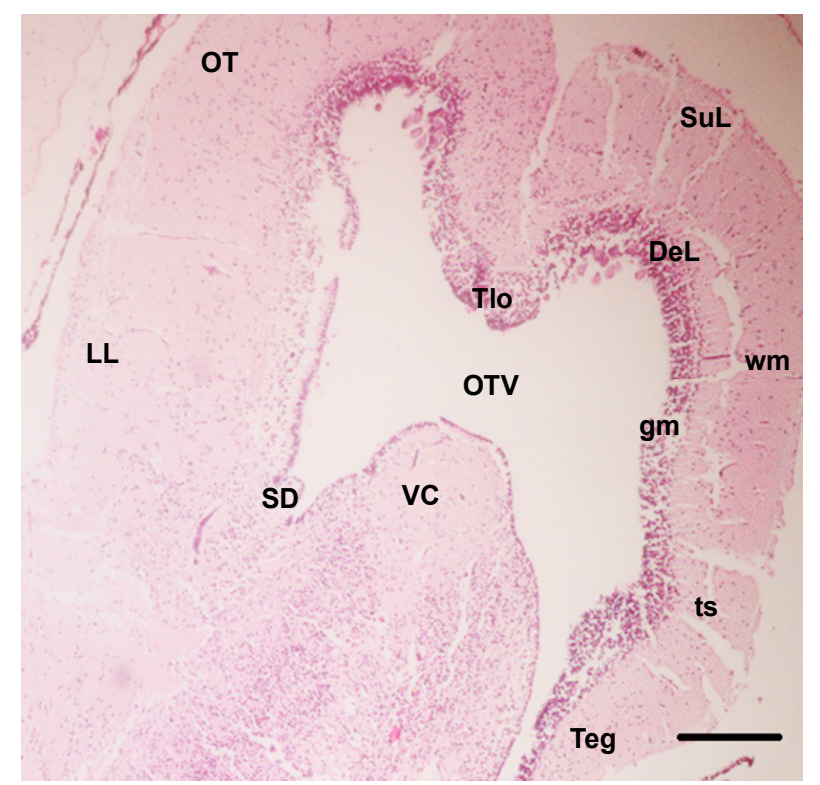

Fig. 9. Frontal section of the midbrain from 54-day-old larvae: $L L=$ lateral lemniscus,

$O T=$ optic tectum, $O T V=$ tectal ventricle, $t s=$ torus semicircularis, $T e g=$ tegmentum, $V C=$ valvula cerebelli, $S u L=$ superficial layer of the optic tectum, $D e L=$ deep layer of optic the tectum, $w m=$ white matter, $g m=$ gray matter, $T l o=$ torus longitudinalis, $S D=$ sacus dorsalis; $H \& E$, bar $=50 \mu \mathrm{m}$.

Table 1. Volume $\left(\mathrm{mm}^{3}\right)$ of the different parts of the midbrain of Huso huso larvae at respective ages, estimated by the Cavalieri principle. Values are presented as mean $\pm \mathrm{SD}, \mathrm{n}=6$

\begin{tabular}{lcccccc}
\hline Age & Midbrain & $\begin{array}{c}\text { Tectal } \\
\text { ventricle }\end{array}$ & Tectum & Tegmentum & $\begin{array}{c}\text { White } \\
\text { matter }\end{array}$ & $\begin{array}{c}\text { Gray } \\
\text { matter }\end{array}$ \\
\hline 1 day & $25.60 \pm 0.28^{\mathrm{a}}$ & $6.06 \pm 0.16^{\mathrm{a}}$ & $9.16 \pm 0.18^{\mathrm{a}}$ & $10.38 \pm 0.10^{\mathrm{a}}$ & $7.40 \pm 0.09^{\mathrm{a}}$ & $12.14 \pm 0.11^{\mathrm{a}}$ \\
3 days & $26.26 \pm 0.23^{\mathrm{b}}$ & $6.58 \pm 0.17^{\mathrm{b}}$ & $9.40 \pm 0.06^{\mathrm{b}}$ & $10.28 \pm 0.09^{\mathrm{b}}$ & $7.82 \pm 0.23^{\mathrm{b}}$ & $11.86 \pm 0.19^{\mathrm{b}}$ \\
6 days & $28.66 \pm 0.44^{\mathrm{c}}$ & $8.26 \pm 0.17^{\mathrm{c}}$ & $10.06 \pm 0.05^{\mathrm{c}}$ & $10.28 \pm 0.14^{\mathrm{c}}$ & $11.48 \pm 0.09^{\mathrm{c}}$ & $8.92 \pm 0.18^{\mathrm{c}}$ \\
15 days & $30.40 \pm 0.33^{\mathrm{d}}$ & $9.22 \pm 0.17^{\mathrm{d}}$ & $10.70 \pm 0.07^{\mathrm{d}}$ & $10.47 \pm 0.11^{\mathrm{d}}$ & $12.64 \pm 0.09^{\mathrm{d}}$ & $8.54 \pm 0.14^{\mathrm{d}}$ \\
21 days & $31.66 \pm 0.30^{\mathrm{e}}$ & $9.92 \pm 0.21^{\mathrm{e}}$ & $11.12 \pm 0.10^{\mathrm{e}}$ & $10.62 \pm 0.05^{\mathrm{e}}$ & $13.44 \pm 0.16^{\mathrm{e}}$ & $8.30 \pm 0.09^{\mathrm{e}}$ \\
54 days & $35.28 \pm 0.28^{\mathrm{f}}$ & $11.96 \pm 0.14^{\mathrm{f}}$ & $12.16 \pm 0.07^{\mathrm{f}}$ & $11.16 \pm 0.07^{\mathrm{f}}$ & $17.04 \pm 0.16^{\mathrm{f}}$ & $6.28 \pm 0.06^{\mathrm{f}}$ \\
\hline
\end{tabular}

Means with different superscripts within a column are statistically significantly different at $\mathrm{P}<0.05$.

selves in the complexity and density of the organ and others can be shown in the development of specific sensory and motor function (Nieuwenhuys, 1998).

The midbrain in H. huso larvae as in other fish and vertebrates consists of a dorsal optic tectum, ventral tegmentum and few appendicular structures as sacus and torus. Its volume, similar to other actinopterygions, is inferior to that of the other parts of brain and is influenced by habitat requirements and behaviours (Nieuwenhuys, 1998). Since this fish lives in the middle depth of sea, the midbrain was less developed compared to other rayfinned fish (Nieuwenhuys, 1998). 
The optic tectum was observed from one day of the age and was separated from tegmentum by the tectal ventricle. In this fish like in others, the optic tectum developed more slowly than the tegmentum. The small optic tectum size was affected by lifestyle and habitat environment. Therefore this part of the brain is smaller than in other pelagic fish species as teleosteans (Nieuwenhuys, 1998). Optic tectum in clupeidae has two complete parts that seem large and distortion happens in their inside structure, but the topologic relation between them remains. In the teleosteans, the optic tectum represents a target region for non-retinal afferent fibres (Butler \& Hodos, 2005). According to living environment of $H$. huso who is characterised with rather low light, it has various adaptive systems such as barbels, big eyes, ability of using electrical and chemical sensory and specially shaped snout (Birstein et al., 1998). Some species have even the ability of using earth magnetic circuit for orientation and migration without using environmental factors (Herring et al., 2000; Lannoo \& Eastman, 2000). The optic tectum in fish, as in other vertebrates, also plays a role in beginning avoidance (anticipation) and escape behaviours. Moving shadows, especially overhead, and looming objects elicit flight reactions that can be eliminated by tectal lesions (Butler \& Hodos, 2005). The cells in optic tectum are arranged in layers with a complex pattern and there is a connection in these layers between the afferent and efferent nerve fibres which are connected to nuclei related to eye muscles and motor-neuron cells of neuromuscular system (Ariens Kappers et al., 1967). It seems that these layers obtain projections from lateral line, retinal ganglion cells and take part in mainly bidirection correlation with other parts of midbrain (Northcutt \&
Davis, 1983). The layering represents the most common interpretation of tectal structure in fish and the most important distinction is between the superficial layers (SO and SFGS) which are mainly visu$\mathrm{al}$, and the deep layers (SGC, SAC, SFPV and SGPV) which are multimodal and motor. Some layers contain many fibres (SO and SAC), others contain some neuronal cell bodies, fibres and synapses (SFGS and SGC), while the innermost layer (SFPV and SGPV) is composed of densely packed neuronal cell bodies as in teleosteans (gold fish) (Kinoshita \& Ito, 2006; Kinoshita et al., 2006). In sturgeons, the cell layers are small and have more large cells, compared to other benthic species (Lannoo \& Eastman, 2000). There was a total of 6 layers and the rod cells were not observed in 54-day-old fish. In the other actinopterygians, the rod cells are important photoreceptor cells that perceive minimum light and as scattered small cells are located between cones cells in deep layers of optic tectum (Nicol, 1989).

The torus longitudinalis (Tlo) was observed in 6-day-old, in the ventro-medial part of optic tectum as a small singular ridge. Its functions are postural control, indication of luminance levels and premotor center for telencephalon (Wullimann, 1994). It has also an important role in balance, vision, coordination and communication between sensory messages and movement responses. In fish, Tlo delivers different messages from resources towards the optic tectum (Banarescu, 1956; Northmore et al., 1983; Bone et al., 1995). In other actinopterygians this ridge is major and associated to visual activities and eye movements. It receives the oculomotor inputs and is part of a sensory circuitry from the tegmentum (Nieuwenhuys, 1998).

Torus lateralis (Tla) was viewed in 15day-old larvae. It is on the lateral surface 
of midbrain in sturgeons and delivers neuron messages to the telencephalon (Northcutt \& Davis, 1983). Torus semicircularis (TS) is a mechanosensory system (Heiligenberg, 1988) and in $H$. huso it was visible from the $1^{\text {st }}$ day of age. In redfish and sturgeons, this structure is large but in teleosteans is of modest size and functions as auditory centre. It contains directionally selective neurons that respond to underwater sound vibrating in a particular direction. TS also contains neurons that respond to the much lower frequencies of water movement that stimulate the lateral line organs (Heiligenberg, 1988).

The tegmentum develops from dilation of the cranial part of medulla oblongata and is located on ventral surface of optic tectum (Ito et al., 2007). It is an important sensory area of fish brain (Helfman et al., 1997) and it has nuclei and nerve fibres that are connected with other brain areas and functions as a transitional zone between midbrain and hindbrain (Northcutt, 1978). The existence of various nuclei can help in secreting cerebrospinal fluid and catecholamines. Sacus vasculitis (SV) was the other visible structure in ventro-medial part of tomentum in 15-day-olds. The SV is a vascular structure and a circumventricular organ similar to the choroid plexus in mammals, with a cuboidal to columnar epithelium and a fibrovascular stroma that is observed in some sturgeons (Gavrilets \& Losos, 2009). It is connected with neurons and ependymal cells and with the help of neighbour nucleus produces cerebrospinal fluid in tectal ventricle (Kotrschal et al., 1983).

Tectal ventricle was visible at 1 day of age and contained cranial choroid plexus. In all fish, the dilation of optic tectum formed the tectal ventricle. In 15-dayolds, a posterior recess together with a part of valvula cerebelli was expanded in this ventricle. In sturgeons, the floor of the tectal ventricle was covered by crown cells (Kotrschal et al., 1983). These are especially cells of ependymal layer and are in contact with cerebrospinal fluid. The sacus dorsalis developed from tectal ventricle, that is in connection with other sensory receptors and other circumventricular organs (Leonhardt, 1980).

According to stereological results, the volume change of midbrain was not extensive. We found a relation between different parts of midbrain. In sturgeons, the sensory area occupies a little volume of brain, because the volume of tectal ventricle was smaller in comparison to that of other species and this showed that the sturgeon requires other senses except its visual sense for living and ecological activities. The studies on different areas of sturgeon brain demonstrate changes and a tendency to use olfactory senses instead of visual senses (Wagner, 2003). Therefore, the share of midbrain from sensory area of the brain is rather small and the fish use the barbels and ampullae lurenzini electrical receptors located on either side of the snout in sturgeons with the functions of finding bait, other ecological and living activities (Northcutt, 1978). The little volume of white matter on 1 and 3 days of age indicate few myelinated nerve fibres and restriction of functions and activities of nervous system.

\section{CONCLUSIONS}

According to data from our research, the sensory area of midbrain was related to ecological activities and in comparison with other ray-finned fishes was not very developed. In general, this study showed that the volume of midbrain increased significantly $(\mathrm{P}<0.05)$ from the $1^{\text {st }}$ to the $54^{\text {th }}$ day of life of beluga sturgeons. 


\section{ACKNOWLEDGEMENTS}

This research is supported by Grant No 455 from Ferdowsi University of Mashhad. Thanks to Dr. Tavighi for the practical assistance and labour on the thesis, to Dr. Shojaei for embryology information, to Dr. Behnam Rassouli for stereological technique.

\section{REFERENCES}

Ariens Kappers, C. U., G. C. Huber \& E.C. Crosby, 1967. The Comparative Anatomy of the Nervous System of Vertebrates Including Man, vol I-III. Hafner. New York, NY: pp. 396-399.

Banarescu, P., 1956. Variation du torus longitudinalis du cerveau chez les poissons téléostéens. Comunicarile Academiei Republicii Populare Române, 6, 893-899.

Bemis, W. E., E. K. Findeis \& L. Grande, 1997. An overview of Acipenseriformes. Environmental Biology of Fish, 48, 25-71.

Birstein, V. J., P. Doukakis \& B. Sorkin, 1998. Population aggregation analysis of three caviar-producing species of sturgeons and implications for the species identification of black caviar, Conservation Biology, 12, 766-775.

Bone, Q., N. B. Marshall \& J. H. S. Blaxter, 1995. Biology of Fishes. Chapman and Hall, London, pp. 332.

Butler, A. B. \& W. Hodos, 2005. Comparative Vertebrate Neuroanatomy, Evolution and Adaptation, $2^{\text {nd }}$ edn, United States of America.

Eastman, J. T., \& M. J. Lannoo, 1995. Diversification of brain morphology in Antarctic notothenioid fishes: Basic descriptions and ecological considerations. Journal of Morphology, 223, 47-83.

Ekstrom, P., C. M. Johnsson \& L. M. Ohlin, 2001. Ventricular proliferation zones in the brain of an adult teleost fish and their relation to neuromeres and migrartion (secondary matrix) zones. Journal of Comparative Neurology, 436, 92-110.
Gavrilets, S. \& J. B. Losos, 2009. Adaptive radiation: Contrasting theory with data. Journal of Science, 323, 732-737.

Gibbs, M. A. \& R. G. Northcutt, 2004. Development of the lateral line system in the shovelnose sturgeon. Brain Behavior Evolution, 64, 70-84.

Gundersen, H. J. G. \& E. B. Jensen, 1987. The efficiency of systematic sampling in stereology and its prediction. Journal of Microscopy, 147, 229-263.

Heiligenberg, W., 1988. The neuronal basis of electrosensory perception and its control of behavioral response in a weakly electric fish. In: Sensory Biology of Aquatic Animals, Springer-Verlag, New York, Berlin, pp. 851-868.

Helfman, G., B. Collette \& D. Facey, 1997. The Diversity of Fishes. Blackwell Publishing, London, pp. 544.

Herring, P. J., I. G. Priede \& P. M. Bagely, 2000. Observations of bioluminescence on the abyssal seafloor. Luminescence, $\mathbf{1 5}$, 211-219.

Ito, H., Y. Ishikawa \& M. Yoshimoto, 2007. Diversity of brain morphology in teleost: Brain and ecological niche. Brain Behavior Evolution. 69, 76-86.

Kimley, A. P., S. C. Beavers \& T. H. Curtis, 2002. Movements and swimming behavior of three species of sharks in La Jolla Canyon, California. Environmental Biology of Fish, 63, 117-135.

Kinoshita, M. \& E. Ito, 2006. Roles of periventricular neurons in retinotectal transmission in the optic tectum. Progress in Neurobiology, 79, 112-121.

Kinoshita, M., E. Ito., A. Urano., H. Ito \& N. Yamamoto, 2006. Periventricular efferent neurons in the optic tectum of rainbow trout. Journal of Comparative Neurology, 499, 546-564.

Kotrschal, K., W. D. Krautgartner \& H. Adam, 1983. Crown cells in the diencephalon of Acipenser ruthenus (Acipenseridae, Chondrostei). Journal für Hirnforschung, 24, 109-120. 
Kotrschal, K., M. J. Van Staaden \& R. Huber, 1998. Fish brains: Evolution and environmental relationships. Reviews in Fish Biology and Fisheries, 8, 373-408.

Lannoo, M. J. \& J. T. Eastman, 2000. Nervous and sensory system correlates of an epibenthic evolutionary radiation in Antarctic notothenioid fishes, genus Trematomus (Perciformes; Nototheniidae). Journal of Morphology, 245, 67-79.

Leonhardt, H., 1980. Ependym und circumventrikuláre organe. In: Handbuch der Mikroskopischen Anatomie des Menschen, Bd. IV: Nerven system, eds A. Oksche \& L. Vollrath eds. Springer, Berlin, pp. 176666.

Nicol, J. A. C., 1989. The eyes of fishes. Oxford University Press, Oxford, pp. 308.

Nieuwenhuys, R., 1998. Chondrostean fishes. In: The Central Nervous System of Vertebrates, Springer Verlag, Berlin, pp. 701757.

Northcutt, R. G., 1978. Brain organization in the cartilaginous fishes. In: Sensory Biology of Sharks, Skates and Rays, eds E. S. Hodgson \& R. F. Mathewson, Office of Naval Research, Arlington, pp. 117-193.

Northcutt, R. G., 1996. The agnathan ark: The origin of craniate brains. Brain, Behavior, Evolution, 48, 237-247.

Northcutt, R. G. \& R. E. Davis, 1983. Fish Neurobiology. University of Michigan Press, Ann Arbor.

Northmore, D. P. M., B. Williams \& H. Vanegas, 1983. The teleostean torus longitudinalis: Responses related to eye movements, visutopic mapping and functional relations with the optic tectum. Journal of Comparative Physiology A, 150, 39-50.

Pinet, P. R., 2002. Invitation to Oceanography, $2^{\text {nd }}$ edn, Jones and Bartlett, Boston, Massachusetts, pp. 324, 326.
Portugues, R. \& F. Engert, 2009. The neural basis of visual behaviors in the larval zebrafish. Current Opinion in Neurobiology, 19, 644-647.

Vazquez, M., F. Rodriguez \& A. Domezain, 2002. Development of the brain of the sturgeon Acipenser naccarii. Piscifactoria de Sierra Nevada, Riofrio, Granada, Spain, Journal of Applied Ichthyology, 18, 275279.

Wagner, H. J., 2003. Volumetric analysis of brain areas indicates a shift in sensory orientation during development in the deepsea grenadier Coryphaenoides armatus. Marine Biology, 142, 791-797.

Wullimann, M. F., 1994. The teleostean torus longitudinalis: A short review on its structure, histochemistry, connectivity, possible function and phylogeny. European Journal of Morphology, 32, 235-242.

Paper received 20.04.2016; accepted for publication 10.06.2016

\section{Correspondence:}

Dr. Zohreh Saadatfar

Department of Basic Science,

Faculty of Veterinary Medicine,

Ferdowsi University of Mashhad, 91779-48974 Mashhad, Iran, tel: 00985138805622 , fax: 00985138763852 , e-mail: saadatfar@ferdowsi.um.ac.ir 